\title{
A PEDAGOGIA DA ALTERNÂNCIA COMO PROPOSTA DE EDUCAÇÃO NO CAMPO: UM ESTUDO NA ESCOLA FAMÍLIA AGRÍCOLA ITAPIREMA EM RONDÔNIA, BRASIL
}

\author{
THE PEDAGOGY OF ALTERNATION AS A PEDAGOGICAL PROPOSAL FOR \\ EDUCATION IN THE FIELD: A STUDY IN THE SCHOOL OF AGRICULTURAL \\ FAMILY ITAPIREMA IN RONDÔNIA, BRAZIL
}

Claudineia Ferreira dos Santos ${ }^{1}$, Charles Carminati de Lima ${ }^{2}$, Yanet Reimondo Barrios $^{3}$ e Daniete Fernandes Rocha ${ }^{4}$

1 Universidade Federal de Rondônia (UNIR) - Campus Professor Francisco Gonçalves Quiles. Rua Manoel Vitor Diniz, 2380 - Jardim São Pedro II - Cacoal - Rondônia - Brasil. Bacharel em Ciências Contábeis, c-l-a-u-d-i-n-e-i-a@hotmail.com

2 Fundação Universidade Federal de Rondônia (UNIR), Professor no Departamento Acadêmico de Ciências Contábeis. Rua da Universidade, 920, Bairro Brizon - Cacoal - Rondônia- Brasil, charles@unir.br

${ }^{3}$ Fundação Universidade Regional de Blumenau (FURB) - Mestre em Desenvolvimento Regional, yanet.barrios89@gmail.com

${ }^{4}$ Faculdade Arnaldo, Professora no Departamento de Ciências Agrárias, Rua Otílio Macedo, 12, Bairro Olhos D’Água, 30.390-200 - Belo Horizonte - Minas Gerais - Brasil, daniet.rocha@gmail.com

\section{ARTICLE INFO}

Article history:

Received 2018-10-30

Accepted 2019-06-17

Available online 2019-06-17
Palavras-chave: Educação Rural. Pedagogia da Alternância. Escola Família Agrícola.

Keywords: Rural Education. Pedagogy of Alternation. Agricultural Family School.

RESUMO. Este estudo evidencia as contribuições da Pedagogia da Alternância na formação educacional e social dos estudantes residentes em uma área rural no Estado de Rondônia. $O$ princípio básico da Pedagogia da Alternância propõe aos estudantes mesclar períodos em regime de internato na escola com outros em casa. Esta proposta foi criada por camponeses da França em 1935. No Brasil, essa iniciativa chegou a partir de missões jesuítas no Espírito Santo, em 1969. Logo se espalhou por 20 estados brasileiros, onde os alunos cursam disciplinas regulares do currículo do Ensino Fundamental e Médio, além das disciplinas específicas relacionadas à agropecuária. Trata-se de um estudo de caso de natureza descritiva, em uma abordagem qualitativa. Para a coleta de dados, foi realizada uma pesquisa documental e entrevistas com professores e com alunos concluintes do curso técnico em agropecuária de uma Escola Família Agrícola (EFA). Constatou-se que a relação de ensino e aprendizagem entre os professores e os estudantes da EFA baseia-se em quatro pilares: Formação integral, Pedagogia da Alternância, Inclusão social e Associativismo. Pelos resultados, pôde-se observar a opção predominante em estudar na Escola Família Agrícola (EFA Itapirema) pelo fato de a escola possuir um curso técnico de preparação profissional. A pesquisa identificou uma carência de investimentos em infraestrutura e materiais pedagógicos na escola. Contudo, destaca-se no estudo que a totalidade dos alunos egressos se mostra satisfeita com a escola.

ABSTRACT. This study evidences the contributions of the Alternation Pedagogy in the educational and social formation of young people living in a rural area in the State of Rondônia. The basic principle of Alternation Pedagogy proposes that students merge periods in boarding school with others periods at home. This methodology was created by peasants from France in 1935. In Brazil, this initiative came from Jesuit missions in the state of Espirito Santo, in 1969. Soon it spread to 20 Brazilian states, 
where students attend regular disciplines of the curriculum of Elementary and Middle School, in addition to the specific disciplines related to agriculture and cattle raising. This is a descriptive case study in a qualitative approach. For the collection of data, a documentary research was carried and interviews were conducted with teachers and with students graduating from the agricultural technical school of an Agricultural Family School (EFA). It was found that the teaching and learning relationship among teachers and students of the EFA is based on four pillars: Integral Education, Alternation Pedagogy, Social Inclusion and Associativism. From the results, it was possible to observe the predominant option in studying at the Agricultural Family School (EFA Itapirema) because the school has a technical course of professional preparation. The research identified a lack of investments in infrastructure and teaching materials in the school. However, it is noteworthy in the study that the totality of the former students is satisfied with the school.

\section{Introdução}

A Pedagogia da Alternância oferece condições para que o aluno da zona rural tenha acesso à educação de forma alternada, permanecendo quinze dias na escola e quinze dias em casa, o que torna mais fácil o seu acesso à escola (NASCIMENTO, 2012). Gnoatto et al (2006) consideram que a Pedagogia da Alternância foi uma das poucas propostas de educação rural voltadas ao desenvolvimento integral do jovem. Ademais, essa metodologia permite que as ações sejam refletidas no grupo, tendo o diálogo como instrumento de participação. Em termos gerais, a Pedagogia da Alternância vem se constituindo numa proposta pedagógica voltada à realidade de jovens e adultos trabalhadores que têm o campo como espaço de vida, trabalho e produção cultural (CORDEIRO; REIS; HAGE, 2011).

As Escolas Famílias Agrícolas (EFAS) têm contribuído para a formação de agentes visando o desenvolvimento rural sustentável e para o avanço da extensão rural no país, pela utilização da Pedagogia da Alternância, que não se enquadra na educação urbana tradicional. As Escolas Famílias Agrícolas no Brasil, associadas ao trabalho, e a partir das experiências dos educandos, de alguma maneira, aportam aos jovens aí formados ensinamentos para que, no futuro, sejam encaminhados ao mundo do trabalho (BIANCHINI, 2005).

Este estudo tem como objetivo identificar a contribuição da Pedagogia da Alternância desenvolvida na Escola Família Agrícola Itapirema, no município de Ji-Paraná, em Rondônia, no enfrentamento dos desafios sociais de seus alunos. Para tanto, busca demonstrar os percalços enfrentados pela escola nas ações que incentivem a prática de educação pela Pedagogia da Alternância.

\section{Pedagogia da Alternância: história, conceito e objetivos}

De acordo com Vergutz (2012), a Pedagogia da Alternância teve suas origens na França, na década de 1930, embasada nas necessidades dos camponeses de uma educação voltada para sua realidade e suas necessidades. Para Nosella (2012), essa nova 
experiência educacional buscava organizar o processo de ensino-aprendizagem alternando dois espaços diferenciados: a propriedade familiar e a escola. Ressalte-se que o mundo ocidental pós-revolução industrial passa a ter como característica o predomínio e valorização da cidade sobre o campo, o que foi agravado na Europa pós Primeira Guerra Mundial e mais tarde (Segunda Guerra), devido à proliferação de atividades urbanoindustriais, provocando ainda mais o êxodo rural.

O Movimento das Casas Familiares Rurais, ligado à pedagogia da alternância, nasceu em 1935, em um pequeno vilarejo da França, a partir da iniciativa de três agricultores e do padre AbbérGranereau, um religioso pároco da vila de Sérignac-Péboudou (filho de agricultores, Granereau tinha um espírito desbravador, era apaixonado pela profissão de agricultor e comprometido politicamente com as causas do desenvolvimento da agricultura e do meio rural). Granereau foi formado pelo pensamento social da Igreja Católica e pelas ideias de Marc Sagner, um dos fundadores do Movimento Sillon.

Gimonet (1999) afirma que a Pedagogia da Alternância é uma alternativa para a educação no campo, mais especificamente em Centros de Formação por Alternância, com o objetivo de promover educação, formação e profissionalização eficazes e concretas, mais apropriadas à realidade rural. A Pedagogia da Alternância "parte da experiência da vida cotidiana (familiar, profissional, social) para ir em direção à teoria, aos saberes dos programas acadêmicos, para, em seguida, voltar à experiência, e assim sucessivamente" (GIMONET, 2007, p. 16). Esse processo de ensino-aprendizagem vem sendo usado na formação de jovens e adultos do campo, visto ser esta uma proposta pedagógica e metodológica capaz de atender as necessidades da articulação entre escolarização e trabalho, propiciando a esses indivíduos o acesso à escola, sem que tenham que deixar de trabalhar (CORDEIRO; REIS; HAGE, 2011).

Com uma metodologia pedagógica específica, a Pedagogia da Alternância prevê momentos no ambiente escolar e momentos no ambiente familiar comunitário, organizados em três etapas sucessivas: a) observar/pesquisar (meio sócio profissional), b) refletir e aprofundar (meio escolar) e c) experimentar/transformar (meio sócio profissional). Neste sentido, a Pedagogia da Alternância também pode ser considerada como a Pedagogia do Encontro.

Para Nascimento (2005), o aspecto mais comum que caracteriza a Pedagogia da Alternância nos Centros de Formação por Alternância existentes no Brasil e no mundo é o período que se alterna entre a formação em casa com o tempo de formação na escola, numa perspectiva de busca constante da sistematização entre a teoria (identificada como conceito) e a prática, o que se considera uma formação integral do jovem adolescente, como sintetizado na Figura 1, a seguir. 


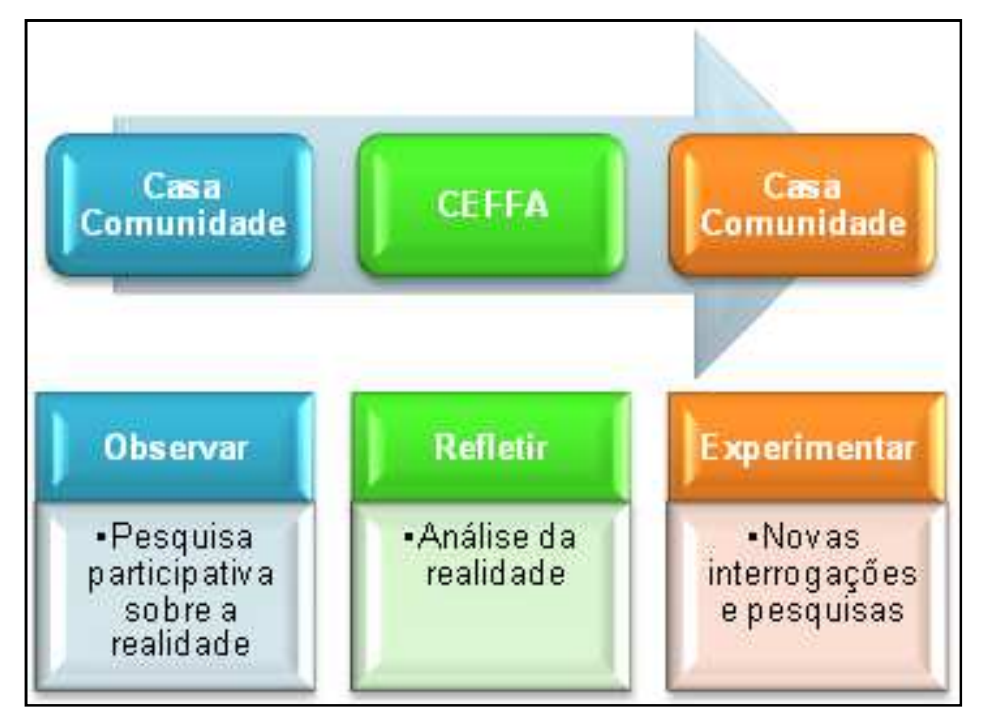

Figura 1 - Diagrama - Pedagogia da Alternância

Fonte: CEFFA ITAPIREMA (2014). Adaptado pelos autores.

No meio sócio profissional familiar acontece a pesquisa e a observação da realidade (busca de saberes e experiências). No ambiente escolar realiza-se a reflexão, problematização e aprofundamentos (sistematização dos conhecimentos). De volta ao meio sócio profissional familiar, o jovem aplica seus conhecimentos na prática, realiza novas experiências e pesquisas (confronto dos saberes teóricos e saberes práticos) (MORO et al, 2007). Ou seja, observa-se uma relação dinâmica entre o momento "observar", o momento "refletir" e, novamente, o momento "experimentar" (CEFFA Itapirema, 2014).

\subsection{A educação rural no Brasil e a Pedagogia da Alternância}

De acordo com Rosa Lucas (2009), a educação no campo foi excluída durante muito tempo das políticas educacionais do país, e, por isso, permaneceu no silêncio por muitos anos. As políticas envolvidas, de alguma forma, negligenciaram a população rural no acesso ao ensino, desconsiderando aspectos importantes como: localidades rurais de difícil acesso e com limitações estruturais para o ensino das crianças e adultos; a distância entre as propriedades e dificuldade de locomoção dos educandos; e a grande necessidade do auxílio dos filhos nas tarefas da casa e da propriedade.

Helana Freitas (2011) localiza o início da educação rural no Brasil por volta de 1930, paralelamente ao começo da industrialização, que gerou um processo de intenso êxodo rural e crescente urbanização da população. Nasce marcada pelo discurso da modernização do campo e da necessidade de adaptar o camponês e suas práticas, sinônimos de atraso, aos novos padrões de agricultura que dariam suporte ao modelo industrial nascente. Desde então, foram inúmeras as propostas educativas formais e informais para o meio rural. Tais 
experiências, porém, sempre foram fragmentadas, algumas vezes sobrepostas, respondendo a interesses conflitantes, tendo papel secundário nas políticas de educação.

De acordo com Moro et al (2007), as Escolas Família Agrícola (EFA) no Brasil, associadas ao mundo do trabalho e a partir das experiências dos educandos, oferecem uma educação que permite aos jovens desenvolver um projeto profissional junto às famílias, e, de alguma maneira, possibilitam sua inserção no campo e sua atuação como agentes de transformação social no meio rural. No trajeto formativo entre casa-escola, o educando vivencia experiências do seu dia a dia, tornando-se elemento crítico formador, sendo agente de um processo dialético de evolução, por meio da participação na produção de novos conhecimentos, através da análise e interação do que se vê na escola e do que se vive na própria comunidade (LIMA, 2012).

De acordo com pesquisa realizada por Carvalho et al (2009) com educandos de uma escola rural no município de Garanhuns, Pernambuco, dos 335 alunos entrevistados, 57\% eram do sexo masculino. Perguntados se pretendiam continuar a vida no campo, $60,5 \%$ responderam ter essa intenção. Com relação às meninas, um percentual de 50,3\% afirmou a pretensão de continuar sua vida no campo, o que demonstra a tendência da prevalência masculina em relação à feminina, quanto à continuação do trabalho no meio rural. O estudo mostra, porém, para ambos os grupos de alunos, uma expectativa expressiva no sentido de darem continuidade ao trabalho no campo.

Carvalho et al (2009) afirmam que ainda existe a vontade da permanência no campo por parte dos jovens, cabendo, assim, um papel fundamental às escolas, com destaque para a Pedagogia da Alternância, que permite o ensino na escola em conjunto com as atividades na comunidade e junto à família.

A história dos Centros Familiares de Formação por Alternância (CEFFAs) mostra uma constante evolução em relação às necessidades dos jovens, a exemplo de mudanças que buscam atender aspectos sociais, profissionais e econômicos (CALVO, 2002). Na formação no CEFFA, pretende-se que o jovem aprenda aquilo que para ele tem sentido ou significado, e estabeleça seu projeto partindo do aspecto profissional, pois este é o que lhe permitirá entrar no mundo dos adultos (o da realidade socioeconômica), um projeto que dê sentido à sua formação e à sua realidade, que permita desenvolver suas próprias soluções.

\subsection{AEscola FamíliaAgrícola (EFA) no Brasil}

O modelo da Escola Família Agrícola (EFA) foi implantado no Brasil pelo Movimento de Educação Promocional do Espírito Santo (MEPES), organização não governamental pioneira na utilização da Pedagogia da Alternância no país (CASTRO, 2007). De acordo 
com Moro et al (2007), a EFA é uma associação de famílias, pessoas e instituições que se unem para promover o desenvolvimento rural sustentável envolvendo os jovens. A EFA tem por finalidade promover a formação integral de todos os envolvidos (adolescentes, jovens e adultos), em um contexto sócio geográfico concreto. Segundo a União das Escolas Famílias Agrícolas do Brasil (UNEFAB, 2014), as Escolas Famílias Agrícolas são constituídas a partir de quatro pilares: 1ํ-- Fortalecimento das associações; 2ํ- Pedagogia da Alternância; $3^{\circ}$ Formação integral; 4ํ- Desenvolvimento Local, conforme Figura 2.

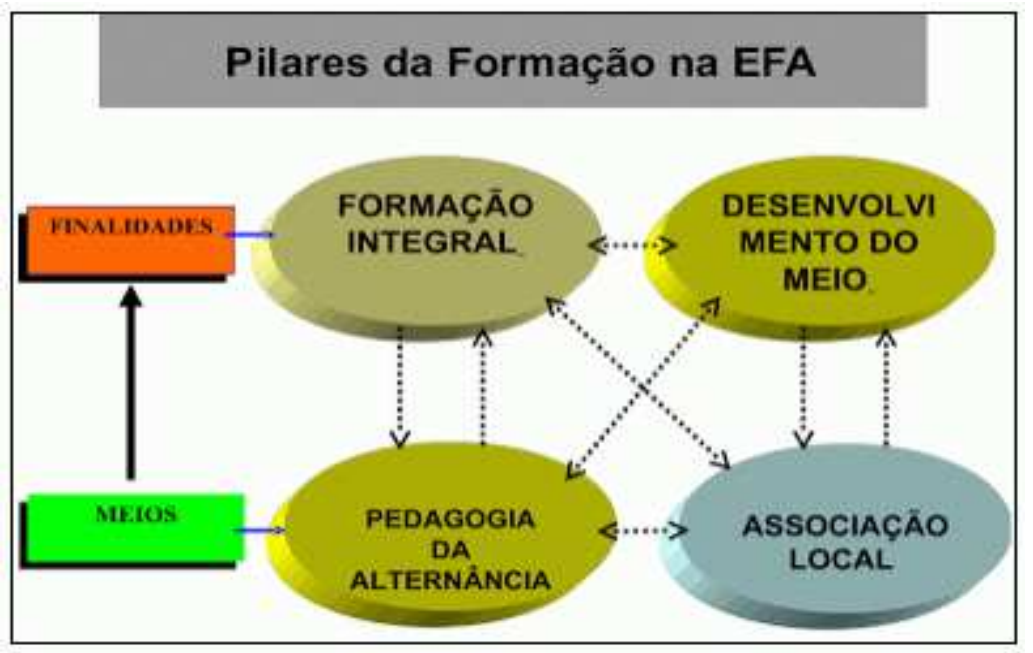

Figura 2 - Representação gráfica dos quatro pilares do EFAS

Fonte: UNEFAB (2014)

A seguir, é demonstrada a abrangência das EFAs nas 5 regiões do país, no Quadro 1, considerando-se o ano de 2014. Conforme observa Nascimento (2012), a Região Nordeste é a que mais se destaca, sobressaindo-se o estado da Bahia, que possui 33 escolas, localizadas principalmente em regiões do interior do estado com maior vulnerabilidade social.

Quadro 1 - A Abrangência das EFAS no Brasil

\begin{tabular}{|c|c|c|c|c|}
\hline Regiões & Estados & Número de EFAS & Subtotal & $\%$ \\
\hline \multirow{5}{*}{ NORTE } & Rondônia & 4 & & \\
\hline & Pará & 2 & & \\
\hline & Amapá & 4 & 13 & 11,7 \\
\hline & Amazonas & 1 & & \\
\hline & Tocantins & 2 & & \\
\hline \multirow{5}{*}{ NORDESTE } & Bahia & 33 & & \\
\hline & Piauí & 8 & & \\
\hline & Sergipe & 2 & 54 & 48,6 \\
\hline & Maranhão & 10 & & \\
\hline & Ceará & 1 & & \\
\hline \multirow{2}{*}{ SUDESTE } & Espírito Santo & 20 & & \\
\hline & Minas Gerais & 14 & & \\
\hline
\end{tabular}




\begin{tabular}{|c|c|c|c|c|}
\hline & Rio de Janeiro & 4 & 39 & 35,1 \\
\cline { 2 - 5 } & São Paulo & 1 & & \\
\hline \multirow{3}{*}{ CENTRO-OESTE } & Goiás & 2 & & \\
\cline { 2 - 5 } & Mato Grosso do Sul & 1 & 4 & 3,6 \\
\cline { 2 - 5 } & Mato Grosso & 1 & 1 & 0,9 \\
\hline SUL & Rio Grande do Sul & 1 & & $100 \%$ \\
\hline BRASIL & & 111 & & \\
\hline
\end{tabular}

Fonte: Elaborado com base na UNEFAB (2014). Adaptado pelos autores.

\section{Procedimentos metodológicos}

Este estudo consistiu em uma pesquisa de natureza qualitativa, no sentido de identificar a contribuição da Pedagogia da Alternância proposta pela EFA Itapirema na formação social e educacional dos estudantes, mediante a percepção de seus professores e alunos. Foi realizada uma pesquisa de campo na Escola Agrícola Itapirema (EFA Itapirema), que atendia, em 2015, aproximadamente, 210 alunos, distribuídos do primeiro ao terceiro ano do Curso Técnico em Agropecuária. Em relação à produção de dados, trabalhou-se primeiramente com a pesquisa documental junto ao Projeto Curricular do Curso Técnico em Agropecuária para caracterização da proposta curricular prevista em seu processo de formaçãoe em outros documentos relacionados com as diretrizes do Curso Técnico em Agropecuária. Também foi pesquisado o estatuto de fundação da EFA Itapirema.

Em um segundo momento, utilizou-se entrevista, por meio de roteiros semiestruturados, para professores e todos os alunos concluintes do Curso Técnico em Agropecuária do ano de 2015. As entrevistas foram realizadas entre os meses de março, abril, maio e junho do mesmo ano. Os entrevistados foram divididos em dois grupos: os 29 alunos concluintes e os 10 professores que ministram aula nesse curso.

Os dados foram tratados segundo a estatística descritiva e demonstrados por meio de gráficos, quadros, tabelas e figuras. A análise baseou-se no referencial teórico.

\section{Resultados e Discussão}

\subsection{Caracterização da Escola Família Agrícola Itapirema de Ji-paraná em Rondônia}

A ideia de implantação da EFA de Itapirema surgiu em 1987, logo após terem sido dados os primeiros passos na implantação da EFA de Cacoal (RO) (CEFFA ITAPIREMA, 2014). O nome da Escola é uma homenagem à tribo indígena Itapirema que habitava a região antes da colonização. Em julho de 1997, foi criada a Associação Promocional da Escola Família Agrícola Itapirema de Ji-Paraná (APEFAIJIP). Nesses 20 anos de existência, 
a escola tem prestado um relevante serviço ao Estado de Rondônia, por meio da educação de jovens e pelo estímulo à integração social de suas famílias (CEFFA ITAPIREMA, 2014).

A EFA Itapirema contribui teoricamente para a formação de seus estudantes com integração social entre escola e família e possui uma visão ecológica e social, procurando conciliar conservação e preservação dos recursos naturais com maior equidade social (VALADÃO E SIENA, 2010).

A EFA Itapirema é mantida pela APEFAIJIP, uma associação comunitária voltada à formação integral de estudantes da área rural. Há uma mensalidade para cada estudante de $R \$ 120,00$, para custear seus próprios gastos com higiene pessoal, alimentação, energia e outros. A direção da APEFAIJIP é formada por membros da escola e da comunidade, eleitos por votação, sendo elencadas as funções de presidente, vice-presidente, tesoureiro e vice tesoureiro, primeira secretária, segunda secretária, suplente do conselho fiscal e representante dos alternantes.

A escola não possui zeladores, cozinheiras e nem jardineiro, pois os próprios alunos são responsáveis por essas funções. É feito um cronograma com todos os horários de aula e atividades a serem realizadas por cada um dos alunos. Na propriedade da escola, que corresponde a dez hectares, os alunos cultivam uma horta para consumo próprio e criam galinhas, porcos e cabritos. Utilizam-se dos frutos cultivados, como o cupuaçu, cacau, acerola e a manga. Além de economizar financeiramente, os professores afirmam que, assim, eles vão aprendendo a ter responsabilidades e a trabalhar em conjunto.

A relação do processo de ensino da EFA Itapirema com a Pedagogia da Alternância pode ser demonstrada pelo diagrama a seguir (Figura 3 ), de acordo com as diretrizes previstas no Projeto Pedagógico do Curso Técnico em Agropecuária.

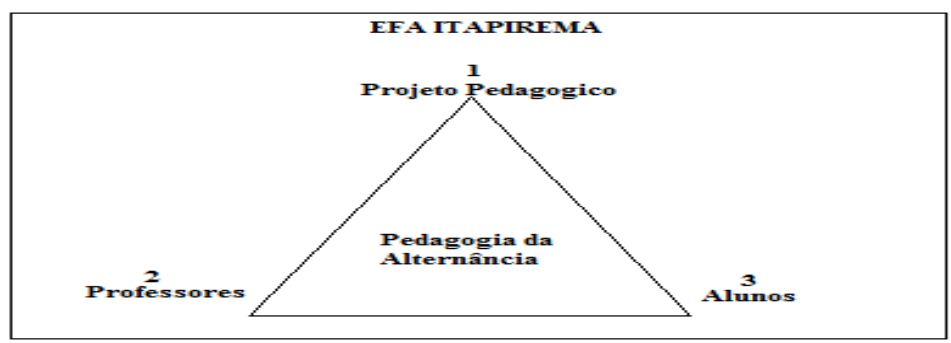

Figura 3 - Demonstração da relação da EFA com a Pedagogia da Alternância

Fonte: Elaborada pelos autores (2015)

\subsection{Contribuição da proposta curricular da EFA na percepção dos professores}

A maioria dos professores provém dos cursos de Ciências Biológicas e Pedagogia. Os licenciados na área de Ciências Biológicas atuam no magistério de biologia e em disciplinas voltadas à educação ambiental, enquanto os licenciados em Pedagogia atuam 
nas disciplinas de Português, Artes, Literatura, História e Sociologia. A maioria do corpo docente compõe-se de não egressos da EFA, é do sexo feminino (63\%) e trabalha na EFA entre um e cinco anos (75\%).O Quadro 2, a seguir, apresenta a caracterização dos professores entrevistados.

\section{Quadro 2 - Identificação dos professores pesquisados}

\begin{tabular}{|c|c|c|c|c|c|c|c|}
\hline \multicolumn{2}{|c|}{ Formação } & \multicolumn{2}{|c|}{$\begin{array}{c}\text { Professores que estudaram } \\
\text { na EFA }\end{array}$} & \multicolumn{2}{|c|}{ Sexo } & \multicolumn{2}{|c|}{$\begin{array}{c}\text { Tempo que trabalha } \\
\text { na EFA }\end{array}$} \\
\hline Pedagogia & $25 \%$ & \multirow{3}{*}{ Egressos } & \multirow{3}{*}{$12 \%$} & \multirow{3}{*}{ Masc. } & \multirow{3}{*}{$37 \%$} & \multirow[t]{3}{*}{$\begin{array}{l}\text { De } 1 \text { a } 5 \\
\text { anos }\end{array}$} & \multirow[t]{3}{*}{$75 \%$} \\
\hline $\begin{array}{l}\text { Ciências } \\
\text { biológicas }\end{array}$ & $37 \%$ & & & & & & \\
\hline Matemática & $13 \%$ & & & & & & \\
\hline $\begin{array}{c}\text { Medicina } \\
\text { veterinária }\end{array}$ & $13 \%$ & \multirow[t]{2}{*}{ Não egressos } & \multirow[t]{2}{*}{$88 \%$} & \multirow[t]{2}{*}{ Fem. } & \multirow[t]{2}{*}{$63 \%$} & \multirow{2}{*}{$\begin{array}{l}\text { De } 12 \text { a } 17 \\
\text { anos }\end{array}$} & \multirow[t]{2}{*}{$25 \%$} \\
\hline Física & $12 \%$ & & & & & & \\
\hline
\end{tabular}

Fonte: Dados da pesquisa (2015)

A maioria dos entrevistados compartilha e afirma a visão da alternância como base para a EFA investigada, tanto pela visão de um "tripé entre ação-reflexão-ação" (38\%), quanto pela percepção de uma "troca de conhecimentos" entre escola e família (37\%).

Em relação à percepção dos professores acerca da contribuição do Projeto Curricular do Curso Técnico em Agropecuária, 62\% destacam que o projeto atende às necessidades dos estudantes em sua atuação produtiva rural. Outros 38\% afirmam que o currículo é frágil na proposta de integração entre a formação técnica profissional e humana de seus estudantes, privilegiando o ensino agropecuário, ou seja, seu caráter técnico.

Sobre as razões para as dificuldades que os estudantes enfrentam com relação à prática dos conhecimentos recebidos na escola, a maioria dos professores considera que esse processo é dificultado pela falta de autonomia dos alunos perante os pais, pela forma como participam no trabalho familiar, pela falta de apoio familiar e outras influências externas. Um quarto dos docentes afirma que tais dificuldades têm como causa questões ligadas à insuficiência de recursos financeiros necessários à aplicação prática das técnicas aprendidas. Uma minoria dos entrevistados (13\%) entende que o problema está relacionado com um acesso escasso a livros e internet. A maioria dos docentes considera que a solução das dificuldades está no estreitamento da parceria entre escola, família e propriedade. 


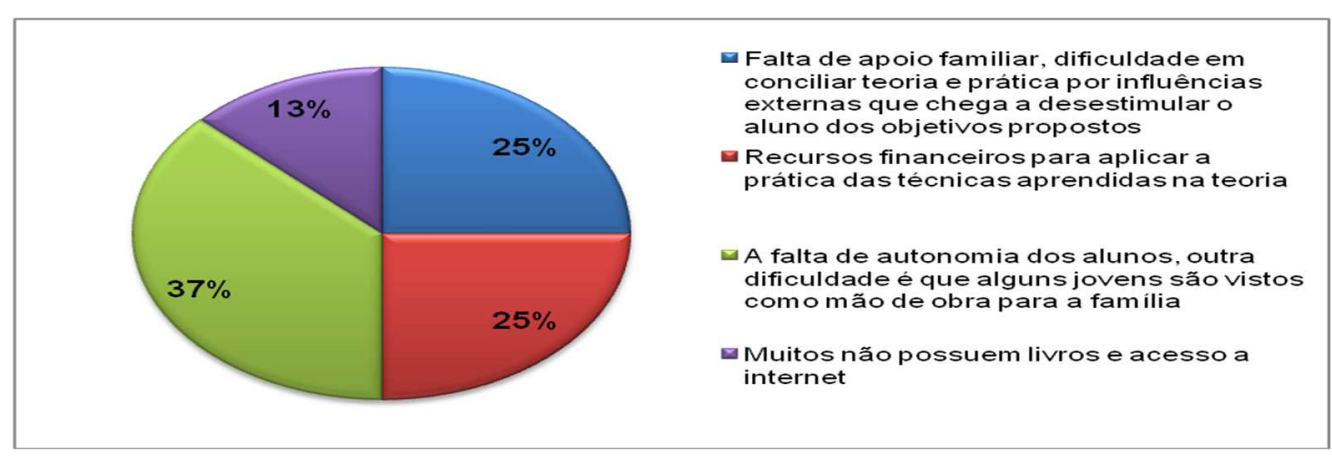

\section{Figura 4 - Dificuldades em praticar os conhecimentos recebidos na Escola}

Fonte: Dados da Pesquisa (2015)

Com relação à posição da EFA quanto aos desafios enfrentados pelos concluintes do curso, no desenvolvimento da atividade agrícola, os professores afirmam que a escola se esforça para contribuir para a inserção profissional e social de seus alunos, conforme Figura 5 , a seguir. Contudo, para os professores, isso pode ser difícil, inclusive porque a proposta da EFA nem sempre é bem aceita pelos familiares dos estudantes, devido a conflitos de ideias, cultura e sucessão familiar.

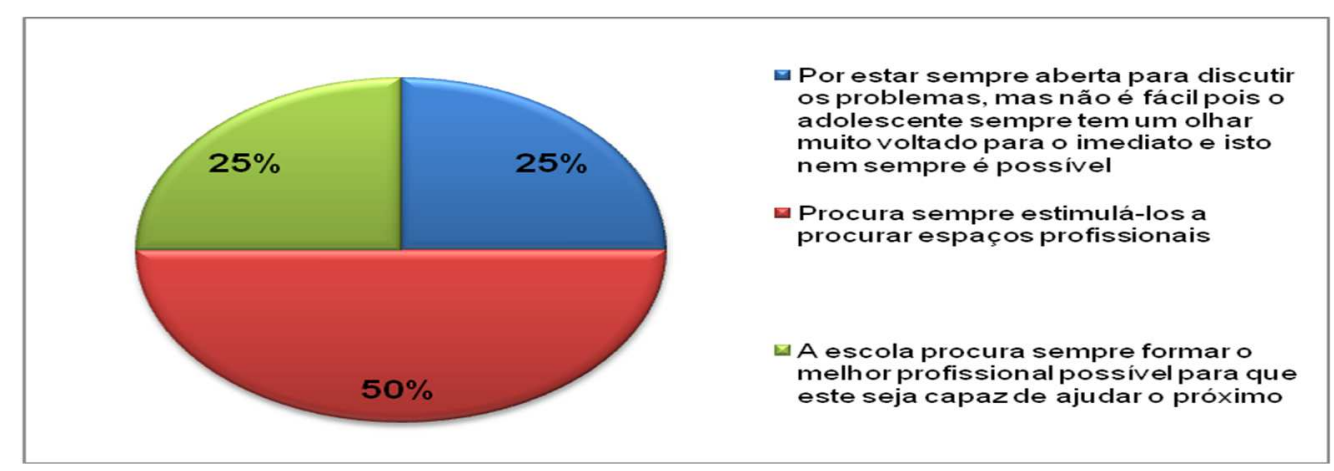

Figura 5 - Escola versus desafios sociais e profissionais de seus egressos

Fonte: Dados da Pesquisa (2015)

Isso contraria a proposta dessa instituição, uma vez que, segundo Moro et al (2007), por meio da associação ao mundo do trabalho e a partir das experiências dos estudantes, as EFAs buscam possibilitar a inserção dos jovens no campo, atribuindo-lhes, de certa forma, um papel como agente de transformação social no meio rural. 


\subsection{Contribuição educativas e socais da EFA Itapirema na percepção dos alunos}

O Quadro 3, a seguir, apresenta o perfil socioeconômico dos estudantes concluintes. Com relação à origem da renda das famílias dos estudantes entrevistados, pode-se destacar que a maior proporção é oriunda da atividade desenvolvida na propriedade rural (48\%), a seguir a advinda do funcionalismo público (24\%) e de serviços em empresa privada $(10 \%)$.

\section{Quadro 3 - Identificação socioeconômica dos estudantes egressos pesquisados}

\begin{tabular}{|c|c|c|c|c|c|c|c|}
\hline \multicolumn{2}{|c|}{ Idade } & \multicolumn{2}{|c|}{$\begin{array}{l}\text { Local onde residem os } \\
\text { entrevistados }\end{array}$} & \multicolumn{2}{|c|}{ Sexo } & \multicolumn{2}{|c|}{ Renda Familiar } \\
\hline $\begin{array}{l}\text { De } 15 \text { a } \\
20 \text { anos }\end{array}$ & $97 \%$ & Zona rural & $97 \%$ & Masc. & $48 \%$ & $\begin{array}{l}\text { Até } 1 \text { salário } \\
\text { mínimo }\end{array}$ & $7 \%$ \\
\hline $\begin{array}{l}\text { De } 21 \text { a } \\
26 \text { anos }\end{array}$ & $3 \%$ & & & & & $\begin{array}{c}\text { De } 1 \text { a } 2 \\
\text { salários } \\
\text { mínimos }\end{array}$ & $24 \%$ \\
\hline $\begin{array}{l}\text { De } 27 \text { a } \\
32 \text { anos }\end{array}$ & $0 \%$ & Zona urbana & $3 \%$ & & & $\begin{array}{l}\text { De } 2 \text { a } 3 \\
\text { salários } \\
\text { mínimos }\end{array}$ & $31 \%$ \\
\hline $\begin{array}{l}\text { Acima } \\
\text { de } 32 \\
\text { anos }\end{array}$ & $0 \%$ & & & rem. & $5<\%$ & $\begin{array}{l}\text { De } 3 \text { a } 4 \\
\text { salários } \\
\text { mínimos }\end{array}$ & $38 \%$ \\
\hline
\end{tabular}

Fonte: Dados da pesquisa (2015)

A pesquisa mostrou que, em sua história constitutiva, a EFA recebeu uma herança cultural devida à influência de agentes ligados a Pastorais da Igreja Católica, a exemplo da Pastoral da Juventude, Pastoral da Terra e do Movimento Terras sem Males. Arroyo (1999) defende a necessidade de se articular a educação rural com as raízes culturais do campo, com a herança coletiva, com a luta por direitos: "direito ao saber e ao conhecimento" (ARROYO, 1999, p.16).

Esses aspectos, em alguma medida, são apontados pelos alunos, quando se considera sua percepção quanto aos objetivos propostos pela Pedagogia da Alternância, como se pode ver na Figura 6. Entretanto, apenas uma minoria percebe os objetivos da Pedagogia da Alternância em relação às escolas tradicionais. 


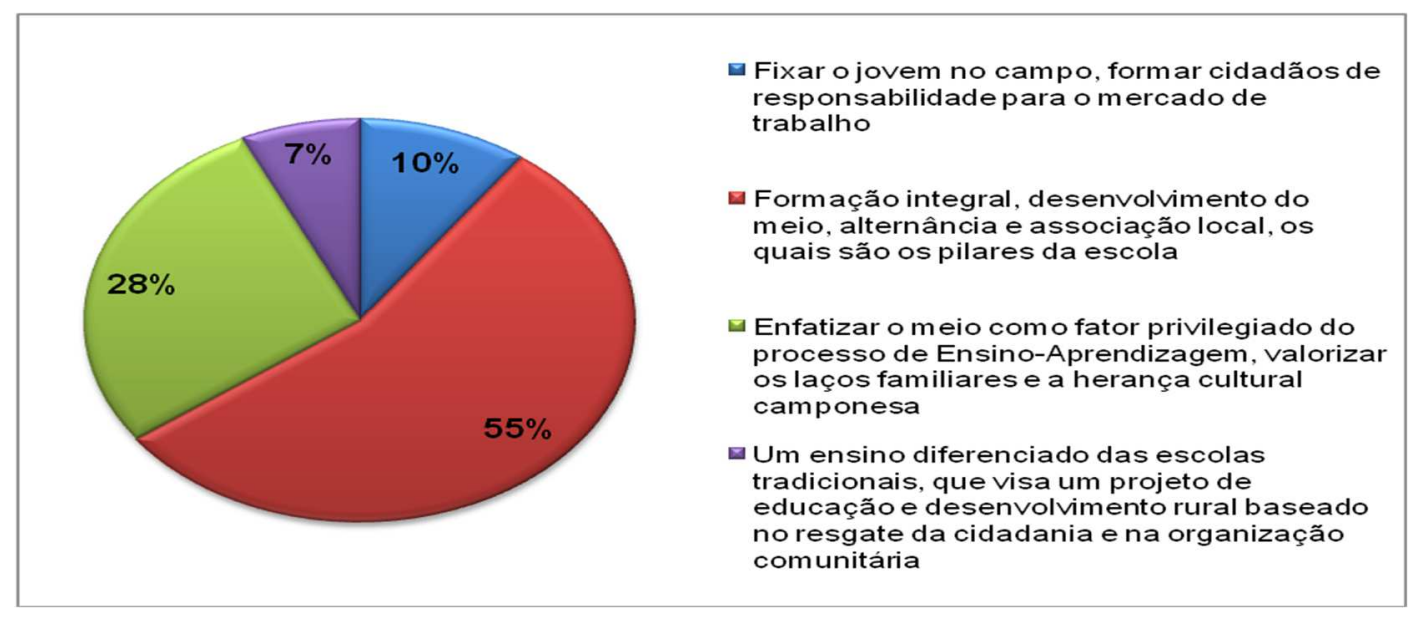

Figura 6 - Objetivos da Pedagogia da Alternância

Fonte: Dados da Pesquisa (2015)

A Figura 7, demonstra a motivação e satisfação dos alunos em relação à EFA.

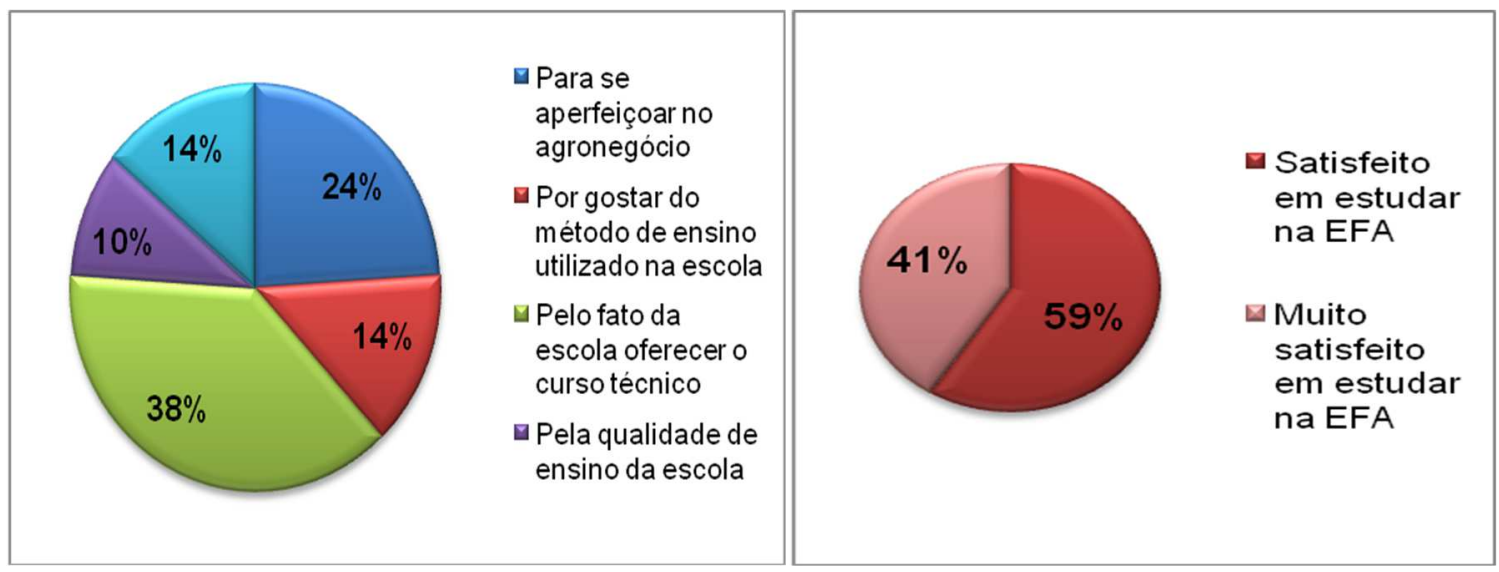

Figura 7 - Motivos e satisfação em estudar na EFA Itapirema

Fonte: Dados da Pesquisa (2015)

Destaca-se como motivação para os entrevistados, o fato de a escola oferecer o Curso Técnico em Agropecuária, que possibilita o acesso ao mercado de trabalho, permite o aperfeiçoamento das ações que envolvem a atividade produtiva do campo (cultivo e comercialização) e facilita o trabalho na propriedade rural em que residem. Uma minoria afirmou optar pelo ensino na EFA em razão da Pedagogia da Alternância. Alguns apontaram o fato de morarem longe da escola, sendo mais difícil o acesso a uma escola com metodologia de ensino regular se tivessem que ir e vir todos os dias.

A totalidade dos alunos egressos de 2015 demonstra satisfação com a formação que receberam na EFA. Os alunos muito satisfeitos destacam que a escola prioriza valores morais como o respeito para com o ser humano e o meio ambiente. Os egressos que afirmam estarem apenas satisfeitos, contudo, apontam que o ensino necessita de melhorias 
pedagógicas que auxiliem nas dificuldades de aplicação teórica e prática. Falta apoio financeiro, entre outras questões. Ressalte-se que a pesquisa identificou que a carência de investimentos de infraestrutura (insuficiência ou inexistência de laboratórios e acervo bibliográfico) e materiais pedagógicos são fatores que prejudicam o desenvolvimento das práticas de ensino

Quando perguntados se pretendem continuar com a atividade produtiva no campo após se formarem, 35\% dos entrevistados afirmaram reconhecer o valor da atividade rural, com pretensão em aperfeiçoá-la e mostrar que é possível se obter adequadas condições de vida pela atividade rural familiar. Entretanto, para outros $65 \%$ desses alunos não ficou clara a intenção de permanecerem na atividade rural, devido a fatores financeiros, estruturais e culturais.

\section{Considerações finais}

A pesquisa demonstra o esforço da EFA no sentido de cumprir o objetivo de alternância, mas ressalta, na percepção de parte dos professores, uma fragilidade na proposta de integração, privilegiando-se o caráter técnico do ensino agropecuário. Quanto aos estudantes, estes compreendem o propósito da proposta pedagógica de ensino: a alternância. Contudo, a opção de estudar na EFA se deu, predominantemente, pelo fato de a escola oferecer um curso técnico de preparo profissional.

Importante notar que todos os egressos se mostram satisfeitos com o ensino da EFA. Observa-se o interesse de parte dos alunos egressos em dar continuidade à atividade produtiva agrícola familiar, mas a maioria não tem clareza sobre a intenção de permanecerem nessa atividade. Por tratar-se de um estudo de caso, os resultados da pesquisa não podem ser generalizados, mas podem contribuir para o debate sobre o tema da educação no país, em especial no que diz respeito aos jovens ligados a atividades do meio rural.

\section{REFERÊNCIAS}

ARROYO, Miguel. A educação básica e o movimento social do campo. In: ARROYO, Miguel; FERNANDES, Bernardo M. Brasília, DF: Coordenação da Articulação Nacional por uma Educação Básica do Campo, 1999. Disponível em http://educampo.miriti.com.br/arquivos/Biblioteca/0081.pdf. Acesso em 15.06.2018.

BIANCHINI, Valter. Alternância: uma educação para o desenvolvimento rural sustentável. In: CONGRESSO INTERNACIONAL, n. 8, 2005. Puerto Iguazú - Argentina e Foz do Iguasul - Brasil. 4 a 6 de maio, 2005. p. 11 a 143. 
CALVO, Pedro Puig. Formação Pessoal e Desenvolvimento local. In: PEDAGOGIA E DESENVOLVIMENTO SUSTENTÁVEL. União Nacional das Escolas Famílias Agrícolas do Brasil 12 a 14 de novembro de 2002. p. 126-146.

CARVALHO, Daniela Moreira; SANTOS, Alyson Brayner; SOUZA JÚNIOR, Jalmir Pinheiro; FERRER, Moises Tenorio. Perspectivas dos jovens rurais: Campo versus cidade. In: CONGRESSO DA SOCIEDADE BRASILEIRA DE ECONOMIA, ADMINISTRAÇÃO E SOCIOLOGIA RURAL, 47, 2009, Porto Alegre, 26 a 30 de julho de 2009. Disponível em: <http://www.sober.org.br/pale stra/13/881.pdf. Acesso em: 10 nov. 2015.

CASTRO, Maurício Barros de. Juventudes Rurais: Cultura e desenvolvimento. Rio de janeiro: Instituto Souza Cruz, 2007.

CEFFA ITAPIREMA. Centro familiar de formação por alternância. A pedagogia da alternância. 2014. Disponível em: shttp://efaitapirema.org/site/o-ensino/a-pedagogia-daalternancia/>. Acesso em: 5 out. 2015.

CEFFA ITAPIREMA. Centro familiar de formação por alternância. História da EFAItapirema. 2014. Disponível em: <http://efaitapirema.org/site/a-escola/historia/>. Acesso em: 5 out. 2015 .

CORDEIRO, Georgina N. K; REIS, Neila da Silva; HAGE, Salomão Mufarrej. Pedagogia da Alternância e seus desafios para assegurar a formação humana dos sujeitos e a sustentabilidade do campo.Revista em Aberto, Brasília, 2011, v. 24, n. 85, p. 115-125, abr. 2011. Disponível em: <http://emaberto.inep.gov.br/index.php/emaberto/index. Acesso em: 26 Out. 2015.

FREITAS, Helana Célia de Abreu. Rumos da Educação do Campo. Revista em Aberto, Brasília, 2011, v. 24, n. 85, p. 35-49, abr. 2011.

GIMONET, Jean-Claude. Nascimento e Desenvolvimento de um Movimento Educativo: As Casas Familiares Rurais de Educação e Orientação. In: SEMINÁRIO INTERNACIONAL SOBRE PEDAGOGIA DA ALTERNÂNCIA. PEDAGOGIA DA ALTERNÂNCIA. Alternância e Desenvolvimento. Salvador, BA: SIMFR/VITAE/UNEFAB. 1999.

Praticar e compreender a Pedagogia da Alternância dos CEFFAS. Petrópolis, RJ: Vozes, 2007.

GNOATTO, Almir Antonio; RAMOS, Celso Eduardo Pereira; PIACESKI, Enelde Elena; BERNARTT, Maria de Lourdes. Pedagogia da Alternância: uma proposta de educação e desenvolvimento no campo. In: XLIV CONGRESSO DA SOBER - SOCIEDADE BRASILEIRA DE ECONOMIA E SOCIOLOGIA RURAL. 23 a 27 de julho de 2006. Fortaleza. Universidade Tecnológica Federal do Paraná. Disponível em: <http://www.sober.org.br/palestra/\%205/941.pdf>. Acesso em: 28 out. 2015.

LIMA, Adriene Viana. Educação do campo e pedagogia da alternância: Algumas considerações metodológicas. Revista Entrelaçando, V.2, № 7, Ano III (2012), p.46-60 Set.-Dez, ISSN 2179.8443.2012. Disponível em: https://pt.scribd.com/document/208690503/4-Educao-Do-Campo-e-Pedagogia-Da-

Alternncia-Adriene. Acesso em: 26nov. 2015.

LUCAS, Rosa ElaneÁntoria. Os desafios da transição de uma educação rural para a educação no e do campo: um estudo de caso na escola estadual de ensino 
fundamental Cândida Silveira Haubman - de tempo integral - Arroio Grande/RS. In: XIX ENCONTRO NACIONAL DE GEOGRAFIA AGRÁRIA. (2009). Disponível em: http://www.geografia.fflch.usp.br/inferior/laboratorios/agraria/

Anais\%20XIXENGA/artigos/Lucas REA.pdf. Acesso em: 22 out. 2015.

MORO, Silvana Maria Laquini; LOPES, Flávio Santos; MORO, Ildranis Laquini; SANTOS, Carla Souza; JESUS, Janinha Jerque de. Pedagogia da alternância e escola família agrícola: Proposta para promoção e o desenvolvimento rural.In: XI ENCONTRO LATINO AMERICANO DE INICIAÇÃO CIENTÍFICA E VII ENCONTRO LATINO AMERICANO DE PÓS-GRADUAÇÃO. p.1-21. São Paulo, 2007.

NASCIMENTO, Claudemiro Godoy do. A educação camponesa como espaço de resistência e recriação da cultura: Um estudo sobre as concepções e práticas educativas da escola família agrícola de Goiás - EFAGO. Dissertação (Mestrado em Educação). Universidade Estadual de Campinas. 2005.

NASCIMENTO, Marivalda da Silva. Educação do campo e a formação do campesino como agente de transformação social/combatendo o êxodo rural e as contribuições das efas na educação do campo: experiências vivenciadas na escola família agrícola de Antônio Gonçalves (EFAG). Trabalho de conclusão de Curso (graduação em Pedagogia) Universidade do Estado da Bahia - UNEB, Bahia, 2012.

NOSELLA, Paolo. Educação no campo: origens da pedagogia da alternância no Brasil. Vitória: EDUFES, 2012.

UNEFAB, União das Escolas Famílias Agrícolas do Brasil. Estudo sobre o Funcionamento dos Centros Familiares de Formação por Alternância no Brasil. Disponível em:https://docs.google.com/file/d/0B07bZIN7afpJdkRuOTdpMzE5Tjg/edit Acesso em: 30 dez. 2014.

VALADÃO, José de Arimatéia; SIENA, Osmar. Contribuições dos centros familiares de formação por alternância para o desenvolvimento rural sustentável. Revista de Gestão Social e Ambiental, №. 1, p. 52-79, jan. - Abr. V.4, 2010.

VERGUTZ, Cristina Luisa Bencke. O caminho da aprendizagem na pedagogia da alternância e o sujeito alternante. In: IX ANPED SUL SEMINÁRIO DE PESQUISA EM EDUCAÇÃO DA REGIÃO SUL. Universidade de Santa Cruz do Sul - UNISC, 2012. 